Revista Brasileira de Agricultura Irrigada v.9, no .4, p.246 - 258, 2015

ISSN 1982-7679 (On-line)

Fortaleza, CE, INOVAGRI - http://www.inovagri.org.br

DOI: $10.7127 /$ rbai.v9n400319

Protocolo 319.15 - 28/04/2015 Aprovado em 30/06/2015

\title{
PRODUÇÃO DE COENTRO EM HIDROPONIA NFT COM O USO DE ÁGUAS SALOBRAS PARA REPOSIÇÃO DO CONSUMO EVAPOTRANSPIRADO
}

\author{
Mairton Gomes da Silva ${ }^{1}$, Tales Miler Soares ${ }^{2}$, Itamar de Souza Oliveira ${ }^{3}$, Jean Cleber da \\ Silva Santos ${ }^{3}$, Jozelmo Sousa Pinho ${ }^{4}$, Fabio Tayrone Oliveira de Freitas ${ }^{4}$
}

\begin{abstract}
RESUMO
Objetivou-se com o presente trabalho avaliar o cultivo de coentro com diferentes disponibilidades de solução nutritiva e níveis de águas salobras para reposição da evapotranspiração da cultura (ETc) em hidroponia NFT (técnica do fluxo laminar de nutrientes). $\mathrm{O}$ delineamento experimental utilizado foi blocos casualizados com cinco repetições, em esquema fatorial $2 \times 4$, totalizando 40 parcelas. Avaliaram-se duas disponibilidades de solução nutritiva (2,75 e 5,50 L por maço de 24 plantas) e quatro níveis de salinidade da água de 0,43 (testemunha); 3,09; 6,87 e 8,53 dS m ${ }^{-1}$. A altura das plantas, as massas de matéria fresca e seca da parte aérea do maço de plantas, das folhas e do caule foram obtidas aos 7, 14, 21 e 24 dias após o transplantio (DAT). Os tipos de águas influenciaram apenas aos 21 DAT na massa de matéria fresca da parte aérea do maço de plantas. Assim, a combinação de água doce para o preparo da solução nutritiva e águas salobras para repor a ETc pode ser uma alternativa para incrementar a produção de coentro em hidroponia. Aos 24 DAT, a maior disponibilidade de solução nutritiva $(5,50 \mathrm{~L})$ aumentou a massa de matéria fresca da parte aérea do maço de plantas em 30,0\% em relação à menor disponibilidade de solução nutritiva $(2,75 \mathrm{~L})$.
\end{abstract}

Palavras-chave: Coriandrum sativum L., cultivo sem solo, salinidade da água.

\section{PRODUCTION OF CORIANDER IN THE NFT HYDROPONIC USING BRACKISH WATERS TO REPLACE THE EVAPOTRANSPIRATION LOSS}

\footnotetext{
ABSTRACT

The aim of this study was to evaluate of coriander cultivation in NFT (nutrient film technique) hydroponic system with different availabilities of nutrient solution and levels of

${ }^{1}$ Tecnólogo em Irrigação e Drenagem, Doutorando em Engenharia Agrícola (Agricultura Irrigada e Recursos Hídricos), Núcleo de Engenharia de Água e Solo/NEAS, Universidade Federal do Recôncavo da Bahia/UFRB, Rua Rui Barbosa, 710, Centro, CEP: 44380-000, Cruz das Almas-BA, e-mail: mairtong @ hotmail.com

${ }^{2}$ Engenheiro Agrônomo, Prof. Doutor, Núcleo de Engenharia de Água e Solo/NEAS, Universidade Federal do Recôncavo da Bahia/UFRB, Cruz das Almas-BA, e-mail: talesmiler@gmail.com

3 Agrônomos pela Universidade Federal do Recôncavo da Bahia/UFRB, Cruz das Almas-BA, e-mail: itamar25souza@gmail.com; jeandinoite@ hotmail.com

${ }^{4}$ Estudantes de Agronomia, Núcleo de Engenharia de Água e Solo/NEAS, Universidade Federal do Recôncavo da Bahia/UFRB, Cruz das Almas-BA, e-mail: jozelmopinho@gmail.com; oibaf.freitas@ hotmail.com
} 
brackish waters to replace the evapotranspiration loss (ETc). The experiment was conducted in a randomized block with five replications, installed in a $2 \times 4$ factorial design, with 40 plots. Studying two availabilities of nutrient solution $(2.75$ and $5.50 \mathrm{~L}$ per bunch of 24 plants) and four levels of salinity of water: 0.43 (control); 3.09; 6.87 and $8.53 \mathrm{dS} \mathrm{m}^{-1}$. Plant height, fresh and dry weight of shoots of the bunch of plants, leaves and of the stem were evaluated at 7 , 14, 21 and 24 days after transplanting (DAT). The types of water influenced at 21 DAT in fresh weight of shoots of the bunch of plants, so the combination of fresh water to prepare of nutrient solution and brackish waters to replace the ETc can be an alternative for increase of the production of coriander in hydroponics. At 24 DAT, the greater availability of nutrient solution $(5.50 \mathrm{~L})$ increased the fresh weight of shoots of the bunch of plants at $30.0 \%$ compared to the lower availability of nutrient solution $(2.75 \mathrm{~L})$.

Keywords: Coriandrum sativum L., soilless cultivation, water salinity.

\section{INTRODUÇÃO}

No semiárido brasileiro existe grande disponibilidade de águas de concentrações salinas inviáveis para utilização direta na irrigação convencional da maioria dos cultivos. Além de proporcionar baixa resposta em condições salinas, a forma tradicional de cultivo potencializa o efeito da salinidade (SANTOS et al., 2010).

É necessário buscar tecnologias alternativas para o uso condizente dessas águas salobras para o maior aproveitamento na produção vegetal, diminuindo consequentemente, os impactos ambientais (SANTOS et al., 2010). Segundo Soares et al. (2007), uma alternativa proposta é o cultivo hidropônico para produção vegetal intensiva, pois nesse tipo de cultivo as culturas podem serem mais tolerantes à salinidade do que no próprio solo, por ter maior disponibilidade de água para as plantas.

Essa região do semiárido destaca-se no cultivo de hortaliças, especialmente o coentro, em que a maioria dos plantios são conduzidos em pequenas áreas com águas provenientes de poços com elevados teores de sais, o que contribui para um baixo rendimento dessa cultura. Logo, diante da limitação de água de boa qualidade para irrigação, espera-se que o cultivo de coentro em sistema hidropônico proporcione o uso sustentável de águas salobras.

O uso de águas salobras em hidroponia em combinação com água doce poderia ser útil para incrementar o rendimento das culturas. Pois de acordo com Soares et al. (2010), o aproveitamento e uso exclusivamente de águas salobras em hidroponia para a reposição da evapotranspi- ração pode ser menos prejudicial às culturas de ciclo curto do que o seu emprego apenas para o preparo da solução nutritiva, pois a salinização gradual seria menos danosa do que a salinidade constante, mas estabelecida desde o início do ciclo.

No sistema hidropônico de cultivo diferentes técnicas são utilizadas quanto à forma de aplicação de solução nutritiva, podendo estas técnicas influenciarem na disponibilidade de água e nutrientes às plantas. A técnica mais utilizada no Brasil é a do NFT (técnica do fluxo laminar de nutrientes), que consiste na passagem de uma lâmina intermitente de solução nutritiva por um leito contendo as plantas (SANTOS et al., 2011).

O cultivo hidropônico representa uma alternativa ao cultivo convencional, com vantagens para o consumidor, produtor e para o ambiente, como obtenção de produtos de alta qualidade, ciclo curto, com maior produtividade, menor gasto de água, de insumos agrícolas e de mão de obra (PAULUS et al., 2010; PAULUS et al., 2012a).

Diante do que foi exposto, objetivou-se com o presente trabalho avaliar o cultivo do coentro em sistema hidropônico NFT com diferentes disponibilidades de solução nutritiva e reposição do consumo evapotranspirado com o uso de águas salobras.

\section{MATERIAL E MÉTODOS}

O experimento foi realizado em casa de vegetação, no Núcleo de Engenharia de Água e 
Solo/NEAS, na Universidade Federal do Recôncavo da Bahia/UFRB, Cruz das Almas, Bahia (12 40' 19" de latitude Sul, 39 06' 23" de longitude Oeste e altitude média de $220 \mathrm{~m}$ ). O clima da região é classificado como úmido a subúmido, com umidade relativa de $80 \%$ e temperatura média anual de $24,1^{\circ} \mathrm{C}$, apresentando pluviosidade média anual de 1.170 $\mathrm{mm}$.

Durante a condução do experimento foi monitorada a temperatura do ar e umidade relativa no interior da casa de vegetação por meio de sensor termohigrômetro, conectado a um datalogger (CR 1000, Campbell Scientific). As médias foram armazenadas a cada 30 minutos.

A umidade relativa do ar instantânea registrada a cada meia hora oscilou da mínima de $30 \%$ a máxima de $91,6 \%$, com média de $71 \%$ (Figura 1A). Os valores de temperatura do ar instantânea oscilaram entre a mínima de $21,1^{\circ} \mathrm{C}$ a máxima de $38^{\circ} \mathrm{C}$, com média da ordem de $27,1^{\circ} \mathrm{C}$. Em $50 \%$ dos dias contataram-se temperaturas máximas instantâneas acima de $35^{\circ} \mathrm{C}$ (Figura 1B). Em trabalhos anteriores com o coentro, registraram-se temperaturas no interior da casa de vegetação acima de $30^{\circ} \mathrm{C}$ (DONEGÁ, 2009; FERREIRA NETO et al., 2014; SILVA, 2014).

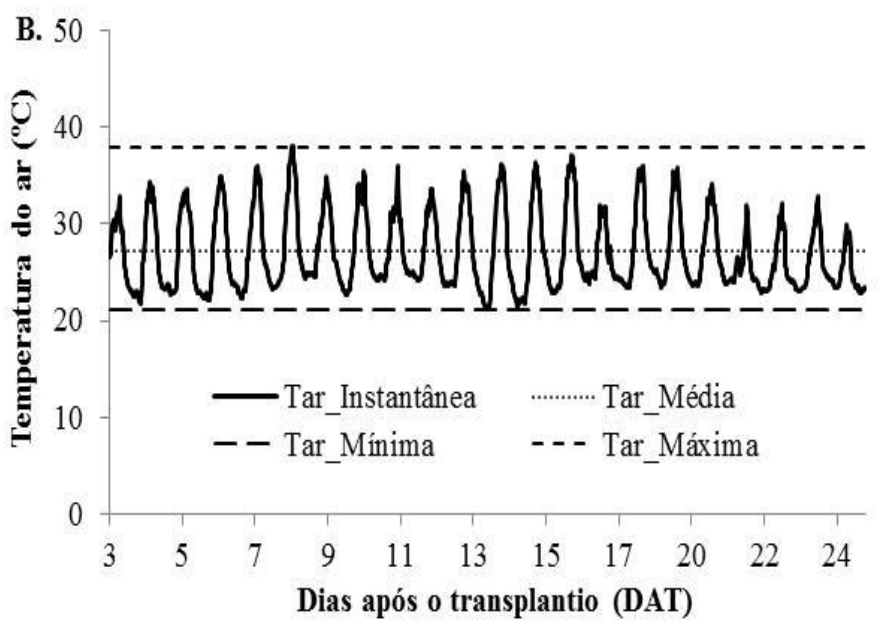

Figura 1. Monitoramento da umidade relativa (A) e temperatura do ar (B).

Utilizou-se uma estrutura hidropônica composta de 40 unidades experimentais. Cada parcela simula um sistema independente de hidroponia NFT, sendo composta por um perfil hidropônico (3 m de comprimento), uma eletrobomba de circulação, um reservatório de solução nutritiva e um tanque de abastecimento automático.

O delineamento experimental utilizado foi em blocos casualizados, com cinco repetições. Os tratamentos foram instalados em esquema fatorial $2 \times 4$, totalizando 40 parcelas, sendo estudados dois níveis de disponibilidade de solução nutritiva $(2,75$ e $5,50 \mathrm{~L}$ por maço de 24 plantas) e quatro níveis de condutividade elétrica da água (CEa): 0,43 (testemunha); 3,09; 6,87 e
$8,53 \mathrm{dS} \mathrm{m}^{-1}$. As águas salobras foram usadas apenas para reposição da evapotranspiração da cultura (ETc). As águas foram salinizadas artificialmente mediante adição de cloreto de sódio $(\mathrm{NaCl})$ à água doce.

A solução nutritiva empregada no cultivo foi adotada a recomendação de Furlani et al. (1999a), para hortaliças folhosas. Avaliou-se a condutividade elétrica e o pH da solução nutritiva a cada três dias.

A solução nutritiva foi bombeada do reservatório até a parte mais alta da bancada por eletrobombas de circulação, acionadas por um temporizador digital programado para ligar o sistema durante $15 \mathrm{~min}$ com intervalos de $10 \mathrm{~min}$, no período das 06 às $11 \mathrm{~h}$ e das 14 às $19 \mathrm{~h}$; das 
11 às $14 \mathrm{~h}$ a irrigação foi constante; e irrigações de $15 \mathrm{~min}$, às $21,23 \mathrm{e} 02 \mathrm{~h}$.

No dia 16 de novembro de 2013 foram semeadas 24 sementes de coentro cv. Verdão em copos de plástico de $50 \mathrm{~mL}$, contendo uma camada de substrato de fibra de coco e outra camada de vermiculita na proporção de 2:1. As mudas foram transplantadas para os perfis hidropônicos aos 10 dias após a semeadura, com oito maços de plantas por parcela.

Para o tratamento de disponibilidade de solução nutritiva de 2,75 L por maço de plantas, o abastecimento nos reservatórios com as água doce e águas salobras foi realizado manualmente e na disponibilidade de solução de 5,50 L foi automático, por meio de abastecedores construídos com tubulação de PVC de diâmetro de $200 \mathrm{~mm}$. Esse sistema permite a saída automática de água para o reservatório de solução nutritiva mediante uma torneira-boia, possibilitando a manutenção do volume contido naquele. $\mathrm{O}$ depósito de abastecimento foi dotado de uma régua graduada, fixada junto a uma mangueira transparente.

Aos 7 e 14 dias após o transplantio (DAT) em cada parcela foi coletado um maço de plantas de coentro e aos 21 e 24 DAT foram coletados dois maços. Cada maço foi representado por 24 plantas, obtendo-se: altura das plantas (AP), massas de matéria fresca da parte aérea do maço de plantas $\left(\mathrm{MFPA}_{\text {maço }}\right)$, das folhas $(\mathrm{MFF})$ e do caule (MFC). As MFF e MFC foram acondicionadas em sacos de papel e colocadas em estufa de circulação forçada, à temperatura de $65^{\circ} \mathrm{C}$ até atingir peso constante para quantificar a matéria seca das folhas (MSF), do caule (MSC) e da parte aérea $\left(\mathrm{MSPA}_{\text {maço}}\right)$, em balanço de precisão $(0,01 \mathrm{~g})$. As medidas de altura das plantas foram determinadas por meio de uma fita métrica.

Os dados foram submetidos ao teste $\mathrm{F}$ da análise de variância. As disponibilidades de solução nutritiva por maço de plantas foram comparadas mediante teste de médias (Tukey a 0,05 de probabilidade). Já o fator salinidade das águas foi estudado mediante análise de regressão, selecionando-se os modelos com base na significância de seus termos, no valor do coeficiente de determinação e no significado agronômico do comportamento. O coeficiente de determinação apresentado no presente texto é para as repetições de cada tratamento e não apenas para às médias.

\section{RESULTADOS E DISCUSSÃO}

\section{Evolução do pH e condutividade elétrica da solução nutritiva}

No dia do transplantio das mudas de coentro, o pH da solução nutritiva foi o mesmo em todas as parcelas, da ordem de 6,14. Durante o ciclo de cultivo, o $\mathrm{pH}$ manteve-se dentro da faixa de 5,39 a 6,34, isso com a menor disponibilidade de solução nutritiva (Figura 2A); e mantendo-se entre 5,31 e 6,14 com a maior disponibilidade de solução nutritiva (Figura 2B).

Inicialmente, em todos os tratamentos partiu-se de uma salinidade inicial igual $(2,03 \mathrm{dS}$ $\left.\mathrm{m}^{-1}\right)$, pois a solução nutritiva foi preparada com água doce $\left(0,43 \mathrm{dS} \mathrm{m}^{-1}\right)$. A aplicação das águas salobras na reposição das perdas por evapotranspiração da cultura (ETc) do coentro hidropônico alterou a salinidade do meio. Ao longo de ciclo de cultivo para a condição de disponibilidade de 2,75 L de solução nutritiva (Figura 2C), o uso de água doce pouco alterou a condutividade elétrica da solução nutritiva, com uma pequena redução da salinidade no final do experimento, o que era previsto devido o consumo de nutrientes ser maior que o aporte de sais dissolvidos nessa água, como verificado em trabalhos anteriores (SANTOS et al., 2010; SOARES et al., 2010; ALVES et al., 2011; PAULUS et al., 2012b; LIRA et al., 2015; 
SOARES et al., 2015). Com a disponibilidade do volume de 5,5 L (Figura 2D), também se constatou pequenas variações na salinidade da solução, sendo no final do experimento o valor muito próximo ao da condição inicial. Essas pequenas variações se devem ao maior volume disponibilizado de solução nutritiva, o que contribui para um maior equilíbrio solução nutritiva à medida que para as plantas absorvem água e nutrientes.
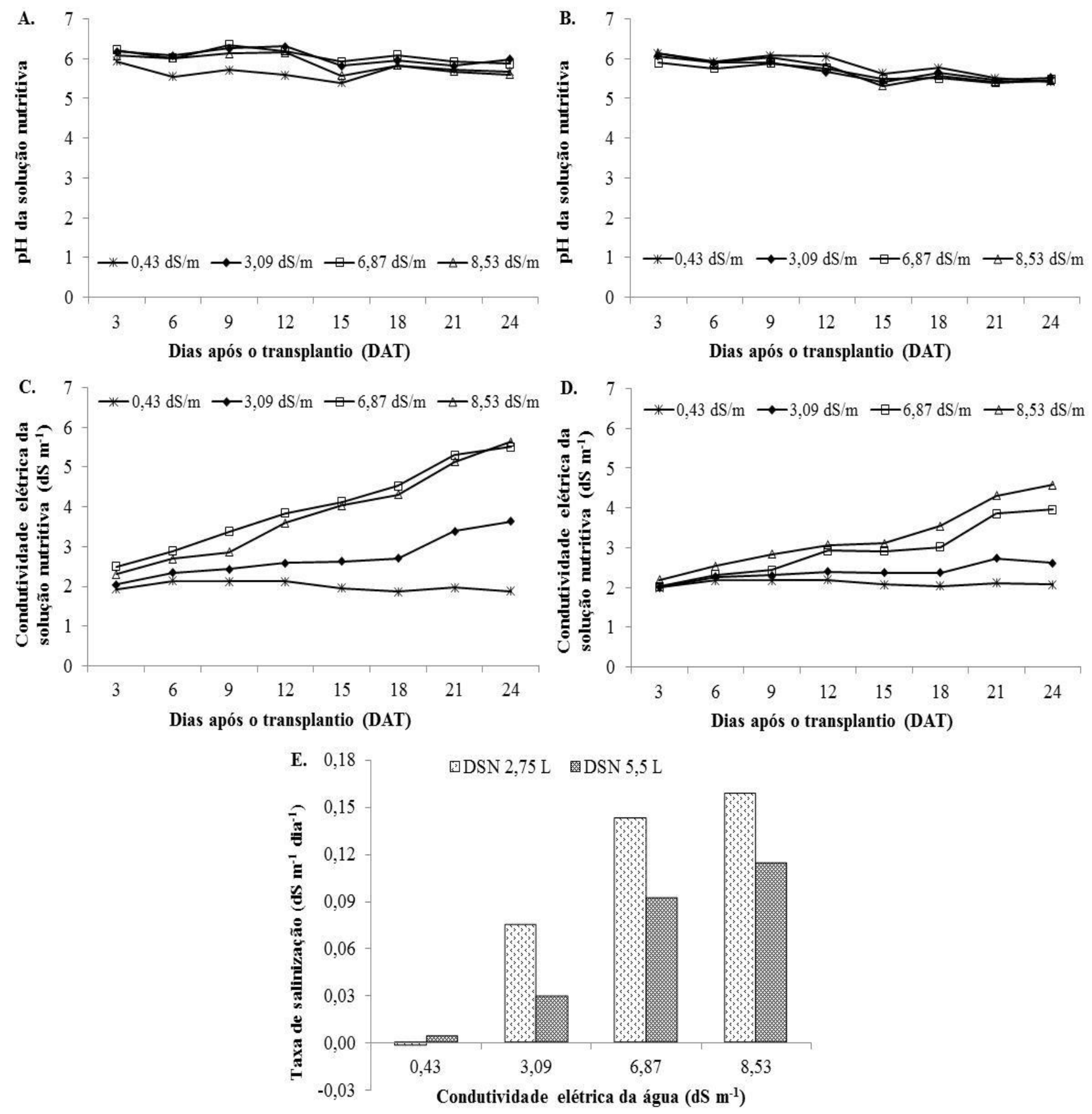

Figura 2. Evolução do pH e da condutividade elétrica da solução nutritiva com a menor $(\mathrm{A}, \mathrm{C})$ e maior $(\mathrm{B}, \mathrm{D})$ disponibilidade de solução e taxa de salinização da solução nutritiva (E) no cultivo de coentro hidropônico. 
Com o uso de águas salobras verificou-se tendência de aumento da salinidade da solução nutritiva em decorrência do aporte de íons ao longo do ciclo (Figuras 2C e 2D), sendo este mesmo tipo de comportamento reportado em trabalhos anteriores em hidroponia (SOARES et al., 2010; ALVES et al., 2011; LIRA et al., 2015; SOARES et al., 2015).

As taxas de salinização diária, calculada entre a condutividade elétrica inicial e final da solução nutritiva foi crescente a partir do uso da

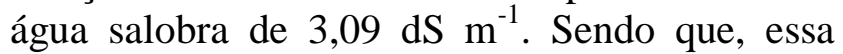
taxa de salinização foi mais evidenciada na menor disponibilidade de solução nutritiva (Figura 2E).

\section{Crescimento}

A combinação de água doce para o preparo de solução nutritiva e águas salobras para reposição da evapotranspiração da cultura do coentro hidropônico (ETc) não influenciou $(p>0,05)$ na altura das plantas (AP) em qualquer período de avaliação. Já a resposta da AP quanto à disponibilidade de solução nutritiva foi influenciada significativamente, com exceção da avaliação realizada aos 7 DAT (Tabela 1).

Tabela 1. Resumos das análises de variância para altura de planta (AP) do coentro hidropônico em função da condutividade elétrica da água (CEa) e disponibilidade de solução nutritiva (DSN), aos 7, 14, 21 e 24 dias após o transplantio (DAT).

\begin{tabular}{cccccc}
\hline \multirow{2}{*}{ FV } & GL & \multicolumn{4}{c}{ Quadrados Médios } \\
\cline { 3 - 5 } & & 7 DAT & 14 DAT & 21 DAT & 24 DAT \\
\hline Bloco & 4 & $0,2556^{\text {ns }}$ & $1,1121^{\text {ns }}$ & $5,1976^{\text {ns }}$ & $8,7218^{\text {ns }}$ \\
CEa & 3 & $0,1023^{\text {ns }}$ & $0,0283^{\text {ns }}$ & $14,7435^{\text {ns }}$ & $27,2194^{\text {ns }}$ \\
DSN & 1 & $0,4203^{\text {ns }}$ & $15,500^{*}$ & $35,5511^{*}$ & $108,2410^{* *}$ \\
CEa x DSN & 3 & $0,7743^{\text {ns }}$ & $0,3143^{\text {ns }}$ & $10,4318^{\text {ns }}$ & $13,7768^{\text {ns }}$ \\
Erro & 28 & 0,5422 & 1,4116 & 6,5571 & 13,9588 \\
CV $(\%)$ & & 7,56 & 6,97 & 8,74 & 11,25 \\
\hline
\end{tabular}

ns - não significativo; **, * - significativo respectivamente a 0,01 e 0,05 de probabilidade pelo teste $\mathrm{F} ; \mathrm{FV}$ - fontes de variação; GL - grau de liberdade; CV - coeficiente de variação.

Há não observância de diferenças significativas do fator disponibilidade de solução sobre a AP aos 7 DAT pode estar relacionada ao baixo consumo hídrico nessa fase inicial de cultivo. Já aos 14, 21 e 24 DAT, o maior crescimento em altura foi promovido com a maior disponibilidade de solução $(5,5 \mathrm{~L}$ por maço de plantas), da ordem de 17,7; 30,2 e 34,9 $\mathrm{cm}$, respectivamente. Quando foi utilizada a menor disponibilidade de solução $(2,75 \mathrm{~L}$ por maço de plantas) ocorreram reduções sobre a altura de plantas da ordem de 7,34; 6,29 e 9,46\%, respectivamente (Figura 3).

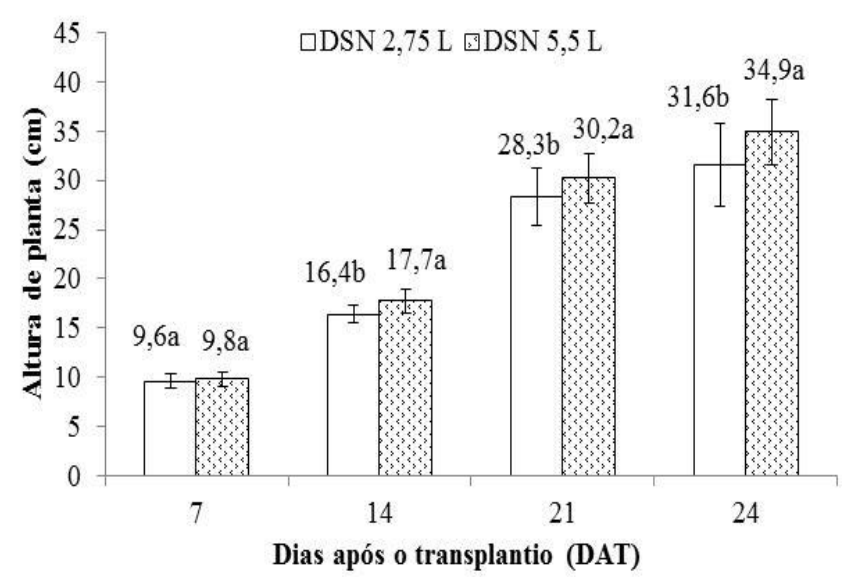


Figura 3. Médias da altura de plantas do coentro hidropônico em função da disponibilidade de solução nutritiva, aos 7, 14, 21 e 24 dias após o transplantio (DAT).

Médias seguidas pela mesma letra apenas dentro do período não diferem estatisticamente a 0,05 de probabilidade (teste de Tukey).

\section{Rendimento de massa de matéria fresca}

A combinação de água doce para o preparo de solução nutritiva e águas salobras para reposição da ETc promoveu efeito significativo sobre a massa de matéria fresca da parte aérea do maço de plantas $\left(\mathrm{MFPA}_{\text {maço }}\right)$, apenas aos 21 DAT e sobre a massa de matéria fresca do caule (MFC) aos 21 e 24 DAT. Efeito significativo da disponibilidade de solução nutritiva foi verificado sobre a MFPA $_{\text {maço, }}$ MFF e MFC, a exceção dos 7 DAT.

Tabela 2. Resumos das análises de variância para as massas de matéria fresca da parte aérea do maço de plantas $\left(\mathrm{MFPA}_{\text {maço}}\right)$, das folhas $(\mathrm{MFF})$ e do caule $(\mathrm{MFC})$ do coentro hidropônico em função da condutividade elétrica da água (CEa) e disponibilidade de solução nutritiva (DSN), aos 7, 14, 21 e 24 dias após o transplantio (DAT).

\begin{tabular}{|c|c|c|c|c|c|c|c|}
\hline \multirow{3}{*}{$\mathrm{FV}$} & \multirow{3}{*}{ GL } & \multicolumn{6}{|c|}{ Quadrados Médios } \\
\hline & & \multicolumn{2}{|c|}{-------MFPA } & \multicolumn{2}{|c|}{ 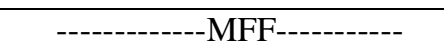 } & \multicolumn{2}{|c|}{--------MFC---------- } \\
\hline & & 7 DAT & $\begin{array}{r}\text { maco } \\
14 \text { DAT }\end{array}$ & 7 DAT & 14 DAT & 7 DAT & 14 DAT \\
\hline Bloco & 4 & $0,0934^{\mathrm{ns}}$ & $3,1314^{\mathrm{ns}}$ & $0,1076^{\mathrm{ns}}$ & $0,5373^{\mathrm{ns}}$ & $0,0396^{\mathrm{ns}}$ & $1,5566^{\mathrm{ns}}$ \\
\hline $\mathrm{CEa}$ & 3 & $0,2465^{\mathrm{ns}}$ & $4,9283^{\mathrm{ns}}$ & $0,1343^{\mathrm{ns}}$ & $1,1902^{\mathrm{ns}}$ & $0,0273^{\mathrm{ns}}$ & $2,2815^{\mathrm{ns}}$ \\
\hline DSN & 1 & $0,0003^{\mathrm{ns}}$ & $46,1605 * *$ & $0,00001^{\mathrm{ns}}$ & $9,2448 * *$ & $0,00006^{\mathrm{ns}}$ & $14,0897 * *$ \\
\hline CEa x DSN & 3 & $0,0266^{\mathrm{ns}}$ & $3,1934^{\mathrm{ns}}$ & $0,0046^{\mathrm{ns}}$ & $0,8311^{\mathrm{ns}}$ & $0,0145^{\mathrm{ns}}$ & $0,8185^{\mathrm{ns}}$ \\
\hline Erro & 28 & 0,4120 & 3,6296 & 0,1370 & 0,7181 & 0,0852 & 1,7732 \\
\hline $\mathrm{CV}(\%)$ & & 16,68 & 13,89 & 16,27 & 12,92 & 18,57 & 18,62 \\
\hline \multirow{2}{*}{ FV } & \multirow{2}{*}{ GL } & \multicolumn{2}{|c|}{-----------MFPA maco-------- } & \multicolumn{2}{|c|}{-------------MFF----------- } & \multicolumn{2}{|c|}{----------MFC--------- } \\
\hline & & $21 \mathrm{DAT}$ & $24 \mathrm{DAT}$ & $21 \mathrm{DAT}$ & $24 \mathrm{DAT}$ & $21 \mathrm{DAT}$ & $24 \mathrm{DAT}$ \\
\hline Bloco & 4 & $26,9629^{\mathrm{ns}}$ & $52,8035^{\mathrm{ns}}$ & $11,4419^{\mathrm{ns}}$ & $44,0959^{\mathrm{ns}}$ & $23,8944^{\mathrm{ns}}$ & $16,5517^{\mathrm{ns}}$ \\
\hline $\mathrm{CEa}$ & 3 & $133,3405^{*}$ & $345,4673^{\mathrm{ns}}$ & $21,9673^{\mathrm{ns}}$ & $79,4312^{\mathrm{ns}}$ & $51,6325^{*}$ & $117,4447 *$ \\
\hline DSN & 1 & $357,6638^{* *}$ & $1599,3396^{* *}$ & $130,4654 * *$ & $331,0276^{* *}$ & $56,0979 *$ & $588,6726^{* *}$ \\
\hline CEa x DSN & 3 & $58,2833^{\mathrm{ns}}$ & $57,0375^{\mathrm{ns}}$ & $7,0090^{\mathrm{ns}}$ & $19,6759^{\mathrm{ns}}$ & $31,6606^{\mathrm{ns}}$ & $37,6852^{\mathrm{ns}}$ \\
\hline Erro & 28 & 43,8721 & 167,7855 & 13,0776 & 39,1650 & 12,4841 & 41,4238 \\
\hline $\mathrm{CV}(\%)$ & & 16,52 & 26,02 & 18,46 & 24,77 & 17,23 & 26,67 \\
\hline
\end{tabular}

ns - não significativo; **, * - significativo respectivamente a 0,01 e 0,05 de probabilidade pelo teste F; FV - fontes de variação; GL - grau de liberdade; CV - coeficiente de variação.

Aos 21 DAT a MFPA $A_{\text {maço }}$ foi reduzida linearmente com o incremento da salinidade das águas para reposição da ETc. Essa redução pode ser considerada baixa, pois foi da ordem de $17,14 \%$ com o maior nível de salinidade $\left(8,53 \mathrm{dS} \mathrm{m}^{-1}\right)$ em relação à testemunha $\left(0,43 \mathrm{dS} \mathrm{m}^{-1}\right)$ (Figura 4A). Os resultados encontrados no presente trabalho corroboram com os reportados por Soares et al. (2010), no cultivo de alface em hidroponia NFT com o uso água doce para o preparo da solução nutritiva combinada com água salobra apenas na reposição da ETc; pois naquele trabalho, a produtividade de massa de matéria fresca da parte aérea reduziu em 19,3\% quando se utilizou a água mais salobra $\left(7,29 \mathrm{dS} \mathrm{m}^{-1}\right)$. Os valores percentuais de reduções no rendimento entre os dois trabalhos são próximos, porém, no presente estudo o maior nível de salinidade da água adotado foi maior em $1,24 \mathrm{dS} \mathrm{m}^{-1}$ em relação ao maior nível utilizado por Soares et al. (2010), mostrando que o coentro cultivado em 
hidroponia NFT é menos sensível à maiores níveis de salinidade da água. Assim como verificado por Cazuza Neto et al. (2014a), pois aqueles autores utilizaram águas salobras tanto para o preparo da solução nutritiva quanto para reposição das perdas da ETc; sendo que o aumento dos níveis das águas salobras reduziram a produção do coentro hidropônico, porém
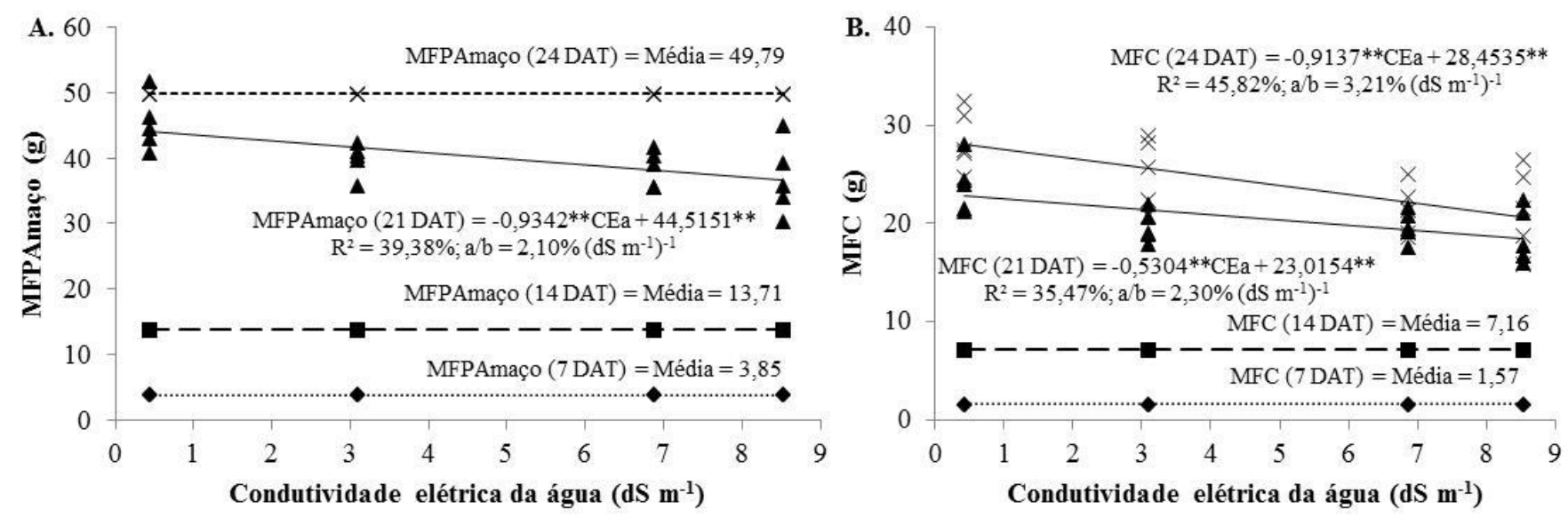

Figura 4. Massas de matéria fresca da parte aérea do maço de plantas (A) e do caule (B) do coentro hidropônico em função da condutividade elétrica das águas, aos 7, 14, 21 e 24 dias após o transplantio (DAT).

** - significativo a 0,01 de probabilidade pelo teste de Student " $t$ ".
A redução na $\mathrm{MFPA}_{\text {maço }}$ aos 21 DAT foi da ordem de 2,10\% para cada aumento unitário de salinidade (em dS $\mathrm{m}^{-1}$ ). Nesse período, a partição da MFC teve redução da ordem de $2,30 \%$ por acréscimo unitário na CEa e aos 24 DAT, da ordem de 3,21\% (Figura 4B).

Aos 24 DAT a não observância de efeito significativo sobre a MFPA $_{\text {maço }}$ com o uso de águas salobras apenas para reposição da ETc pode indicar uma alternativa para o incremento da produção de hortaliças em hidroponia. Assim como já confirmado por Alves et al. (2011) no cultivo de alface em hidroponia NFT; em que o uso de água doce para o preparo da solução nutritiva em combinação com águas salobras para repor a ETc não promoveram diferenças significativas sobre o rendimento da alface. Logo, para os produtores hidropônicos que têm sem efeitos depreciativos a qualidade visual do produto, à exceção das plantas produzidas com água de 7,73 $\mathrm{dS} \mathrm{m}{ }^{-1}$, cujas folhas mais velhas exibiram sintomas de queima dos bordos. disponibilidade de água salobra e restrição de água doce, os resultados apresentados no presente podem servir de indicativo para a exploração da água salobra, sendo que essas águas poderiam ser combinadas com água de chuva.

Quanto à disponibilidade de solução nutritiva, assim como reportado para a variável altura das plantas, a maior disponibilidade $(5,5 \mathrm{~L}$ por maço de plantas) promoveu maiores valores médios de MFPA $_{\text {maço }}$ (Figura 5A), MFF (Figura 5B) e MFC (Figura 5C). Já quando foi utilizada menor disponibilidade de solução nutritiva $(2,75$ L por maço de plantas), a MFPA maço reduziu em 14,$54 ; 13,88$ e 22,55\%, aos 14, 21 e 24 DAT, respectivamente. A redução na $\mathrm{MFPA}_{\text {maço }}$ aos 14 DAT, se deu tanto pela partição da MFF $(13,64 \%)$ quanto pela partição de MFC (15,35\%); já aos 21 DAT, a MFF (16,87\%) teve maior influência na redução do que a MFC 
$(10,93 \%)$ e, aos 24 DAT foi a partição da MFC

$(27,46 \%)$ que teve maior influência do que a

MFF (20,43\%), respectivamente.
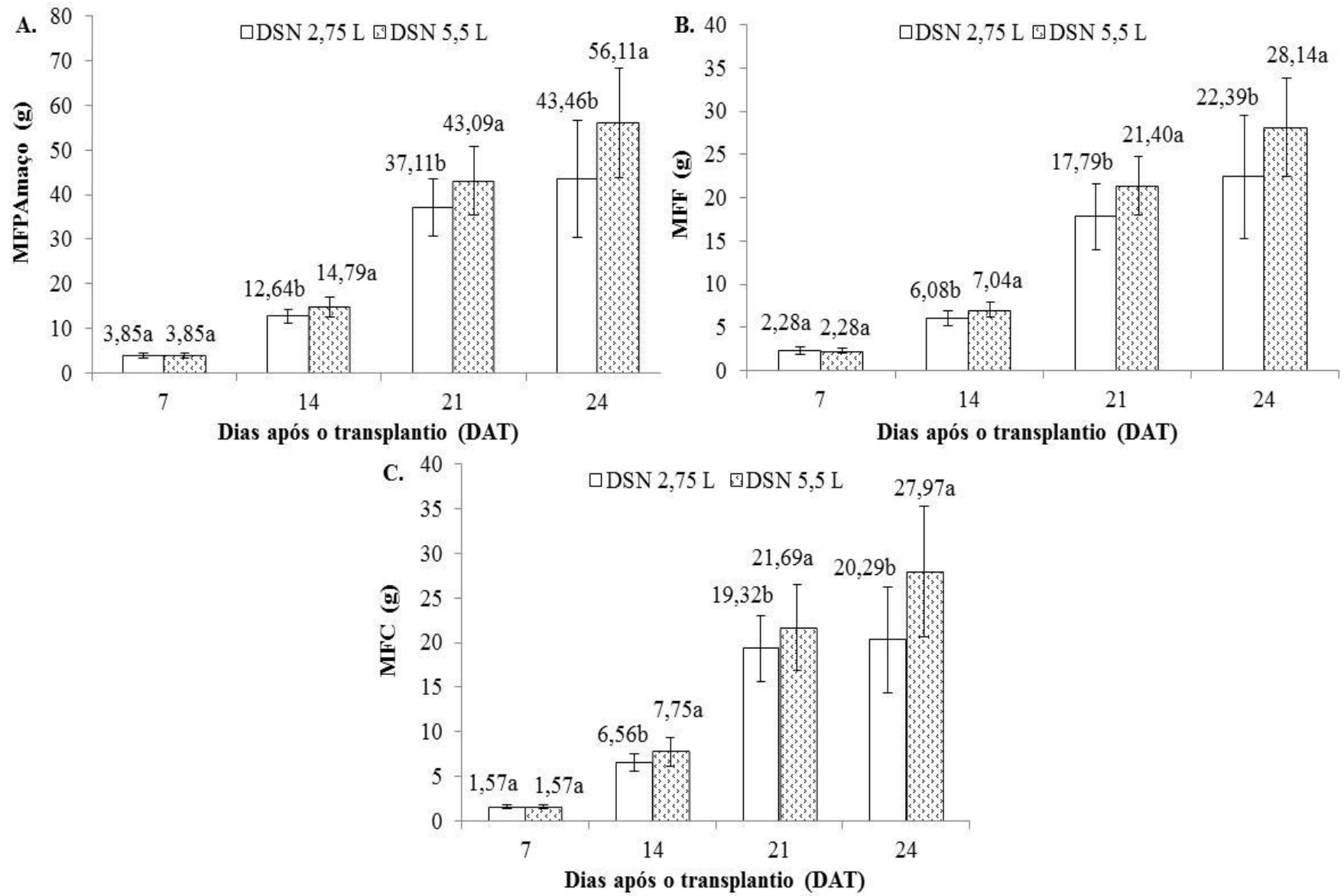

Figura 5. Massas de matéria fresca da parte aérea do maço de plantas (A), das folhas (B) e do caule (C) do coentro hidropônico em função da disponibilidade de solução nutritiva, aos 7, 14, 21 e 24 dias após o transplantio (DAT). Médias seguidas pela mesma letra apenas dentro do período não diferem estatisticamente a 0,05 de probabilidade (teste de Tukey).

Furlani et al. (1999b) citam que no reservatório o volume mínimo de solução nutritiva para plantas de pequeno e médio porte como o coentro dever ser entre 0,25 a $0,5 \mathrm{~L}$, ou seja, os valores utilizados no presente trabalho estão muito acima dos supracitados pelos autores. $\mathrm{Na}$ maioria das pesquisas em hidroponia, geralmente, são disponibilizados grandes volumes de solução nutritiva para as plantas: com alface de 5,5 L (SANTOS et al., 2010), de 5,3 L (SOARES et al., 2010), de 4,6 L (ALVES et al., 2011) e de 3,0 L (PAULUS et al., 2012b); com rúcula de 4,5 L (SILVA et al., 2011); com coentro de 5,5 L (CAZUZA NETO et al., 2014ab); e como são culturas de ciclo rápido, não há necessidade de correção nutricional. Porém, estudos devem ser conduzidos visando alcançar a melhor relação custo-benefício, ou seja, o quanto representa os nutrientes no custo de produção do coentro.

\section{Rendimento de massa de matéria seca}

A combinação de água doce para o preparo de solução nutritiva e águas salobras para 
reposição da ETc não promoveu efeito significativo $(\mathrm{p}>0,05)$ sobre as massas de matéria seca da parte aérea do maço de plantas $\left(\mathrm{MSPA}_{\text {maço}}\right)$, das folhas (MSF) e do caule (MSC). Efeito significativo da disponibilidade de

Tabela 3. Resumos das análises de variância para as massas de matéria seca da parte aérea do maço de plantas $\left(\mathrm{MSPA}_{\text {maço}}\right)$, das folhas $(\mathrm{MSF})$ e do caule $(\mathrm{MSC})$ do coentro hidropônico em função da condutividade elétrica da água (CEa) e disponibilidade de solução nutritiva (DSN), aos 7, 14, 21 e 24 dias após o transplantio (DAT).

\begin{tabular}{|c|c|c|c|c|c|c|c|}
\hline \multirow{3}{*}{ FV } & \multirow{3}{*}{ GL } & \multicolumn{6}{|c|}{ Quadrados Médios } \\
\hline & & \multicolumn{2}{|c|}{ 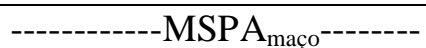 } & \multicolumn{2}{|c|}{--------------MSF----------- } & \multicolumn{2}{|c|}{-----------MSC--------- } \\
\hline & & 7 DAT & 14 DAT & $7 \mathrm{DAT}$ & 14 DAT & 7 DAT & 14 DAT \\
\hline Bloco & 4 & $0,0023^{\text {ns }}$ & $0,0543^{\mathrm{ns}}$ & $0,0019^{\mathrm{ns}}$ & $0,0255^{\mathrm{ns}}$ & $0,0005^{\mathrm{ns}}$ & $0,0060^{\mathrm{ns}}$ \\
\hline $\mathrm{CEa}$ & 3 & $0,0035^{\text {ns }}$ & $0,0337^{\mathrm{ns}}$ & $0,0018^{\mathrm{ns}}$ & $0,0174^{\mathrm{ns}}$ & $0,0004^{\mathrm{ns}}$ & $0,0042^{\mathrm{ns}}$ \\
\hline DSN & 1 & $0,0011^{\mathrm{ns}}$ & $0,1404^{*}$ & $0,0005^{\mathrm{ns}}$ & $0,0563 *$ & $0,0001^{\mathrm{ns}}$ & $0,0189^{\mathrm{ns}}$ \\
\hline CEa x DSN & 3 & $0,0012^{\mathrm{ns}}$ & $0,0250^{\mathrm{ns}}$ & $0,0001^{\mathrm{ns}}$ & $0,0161^{\mathrm{ns}}$ & $0,0006^{\mathrm{ns}}$ & $0,0027^{\mathrm{ns}}$ \\
\hline Erro & 28 & 0,0032 & 0,0290 & 0,0016 & 0,0100 & 0,0006 & 0,0056 \\
\hline $\mathrm{CV}(\%)$ & & 16,36 & 12,65 & 16,03 & 11,90 & 24,49 & 14,70 \\
\hline \multirow[t]{2}{*}{ FV } & \multirow[t]{2}{*}{ GL } & \multicolumn{2}{|c|}{ 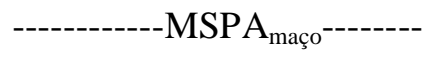 } & \multicolumn{2}{|c|}{------------MSF----------- } & \multicolumn{2}{|c|}{----------MSC--------- } \\
\hline & & $21 \mathrm{DAT}$ & $24 \mathrm{DAT}$ & $21 \mathrm{DAT}$ & $24 \mathrm{DAT}$ & $21 \mathrm{DAT}$ & $24 \mathrm{DAT}$ \\
\hline Bloco & 4 & $0,1353^{\text {ns }}$ & $0,1910^{\mathrm{ns}}$ & $0,1179^{\mathrm{ns}}$ & $0,2558^{\mathrm{ns}}$ & $0,0712^{\mathrm{ns}}$ & $0,0648^{\text {ns }}$ \\
\hline $\mathrm{CEa}$ & 3 & $0,4294^{\mathrm{ns}}$ & $1,2344^{\mathrm{ns}}$ & $0,1234^{\mathrm{ns}}$ & $0,5171^{\mathrm{ns}}$ & $0,1073^{\mathrm{ns}}$ & $0,1583^{\text {ns }}$ \\
\hline DSN & 1 & $1,4258^{*}$ & $5,8194 * *$ & $0,8369 * *$ & $2,3112 * *$ & $0,0780^{\mathrm{ns}}$ & $0,7958 *$ \\
\hline CEa $\times$ DSN & 3 & $0,2135^{\text {ns }}$ & $0,1196^{\mathrm{ns}}$ & $0,0405^{\mathrm{ns}}$ & $0,0644^{\mathrm{ns}}$ & $0,0834^{\mathrm{ns}}$ & $0,0248^{\text {ns }}$ \\
\hline Erro & 28 & 0,2205 & 0,7264 & 0,0932 & 0,2725 & 0,0408 & 0,1245 \\
\hline CV (\%) & & 14,21 & 20,34 & 15,32 & 20,59 & 15,42 & 21,32 \\
\hline
\end{tabular}

ns - não significativo; **, * - significativo respectivamente a 0,01 e 0,05 de probabilidade pelo teste F; FV - fontes de variação; GL - grau de liberdade; CV - coeficiente de variação.

Diante da escassez de água de boa qualidade, a estratégia de combinação de águas salobras e doce pode ser uma alternativa para incrementar a produção hidropônica. Investigações deste tipo têm sido conduzidas, como nos estudos de Soares et al. (2010) e Alves et al. (2011); de acordo com aqueles autores, no cultivo de culturas de ciclo curto quando forem disponíveis águas doce e salobras, é mais produtivo empregar a doce para o preparo da solução nutritiva foi verificado sobre a MSPA $_{\text {maço }}$ e MSF, a exceção dos 7 DAT; sobre a MSC apenas aos 24 DAT (Tabela 3). 
Assim como verificado para o rendimento com base em massa de matéria fresca, o maiores rendimentos de $\mathrm{MSPA}_{\text {maço }}$ (Figura 6A), MSF (Figura 6B) e MSC (Figura 6C) foram obtidos com a maior disponibilidade de solução nutritiva por maço de plantas $(5,5 \mathrm{~L})$.

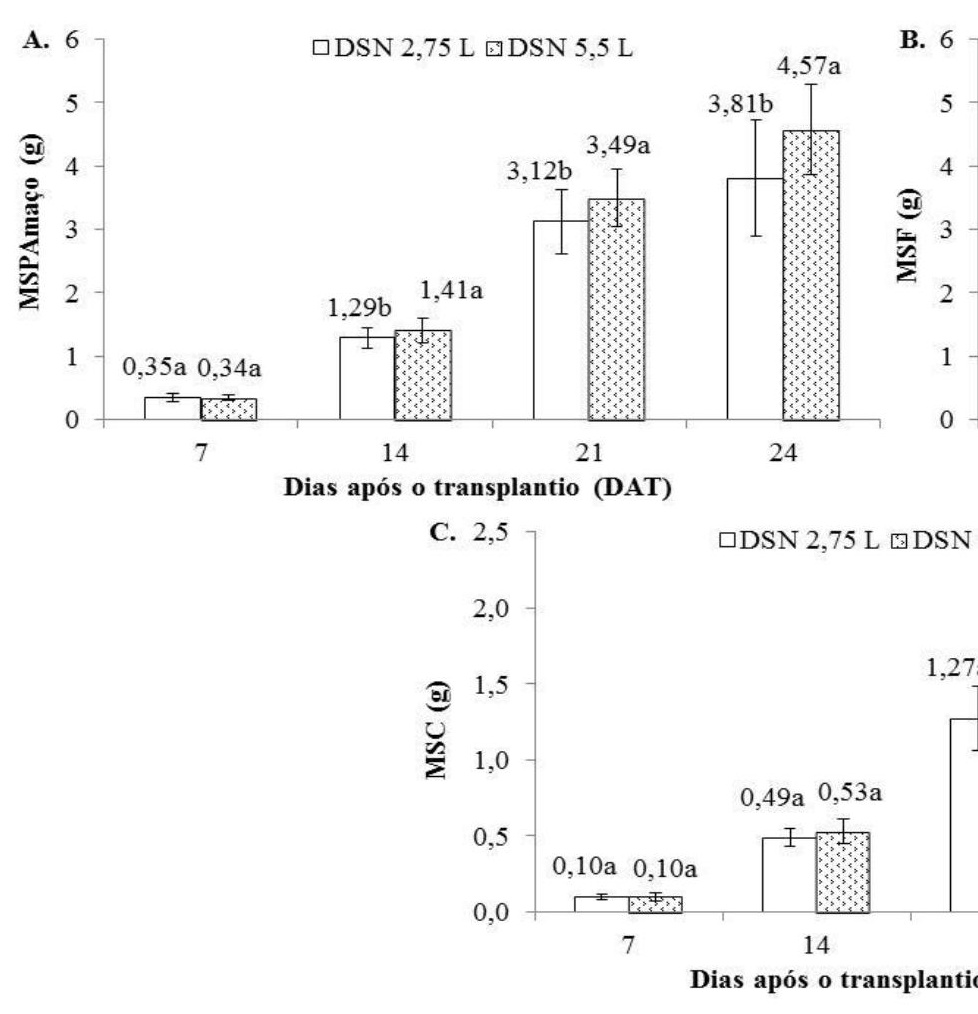

Figura 6. Massas de matéria seca da parte aérea do maço de plantas (A), das folhas (B) e do caule (C) do coentro hidropônico em função da disponibilidade de solução nutritiva, aos 7, 14, 21 e 24 dias após o transplantio (DAT). Médias seguidas pela mesma letra apenas dentro do período não diferem estatisticamente a 0,05 de probabilidade (teste de Tukey)

Aos 14, 21 e 24 DAT quando foi utilizada a menor disponibilidade de solução nutritiva $(2,75 \mathrm{~L})$ ocorreu redução na $\mathrm{MSPA}_{\text {maço }}$ da ordem de 8,$51 ; 10,60$ e $16,63 \%$, respectivamente. Nestes mesmos períodos de tempo, verificou-se redução na MSF da ordem de 9,09; 13,55 e $17,63 \%$, respectivamente. Aos 24 DAT, a MSC reduziu em $16,11 \%$ quando foi utilizada a menor disponibilidade de solução nutritiva de $2,75 \mathrm{~L}$.

\section{CONCLUSÕES}

Não foram constatados sintomas de toxidez ou deficiência mineral que pudessem ser atribuídos à salinidade da água e que levassem ao comprometimento da qualidade do produto.

A combinação de água doce para o preparo de solução nutritiva e águas salobras para reposição do volume evapoptranspirado pode ser uma estratégia eficaz para o incremento da produção de coentro em hidroponia, pois a cultura não mostrou-se sensível à salinização gradual da solução nutritiva com este tipo de estratégia.

O maior volume de solução nutritiva disponibilizado de 5,5 L por maço de plantas promoveu maior crescimento e rendimento do coentro hidropônico.

\section{AGRADECIMENTOS}

À Fundação de Amparo à Pesquisa do Estado da Bahia (FAPESB) pela concessão da bolsa de estudo ao primeiro autor (Pedido $\mathrm{N}^{\circ}$ 6624/2012: Termo de Outorga de Bolsa (T.O.B.) - No BOL2670/2012) e pela concessão do auxílio Dissertação (Edital FAPESB No 005/2014: Pedido $N^{\circ}$ 1675/2014: Termo de Outorga - N $^{\circ}$ APR0044/2014).

À FAPESB, ao Instituto Nacional de Ciência e Tecnologia em Salinidade (INCTSAL) e ao Conselho Nacional de Desenvolvimento Científico e Tecnológico (CNPq) pelo apoio financeiro à infraestrutura hidropônica (Edital Universal 14/2011; Processo 484645/2011-0). 


\section{REFERÊNCIAS BIBLIOGRÁFICAS}

ALVES, M. S.; SOARES, T. M.; SILVA, L. T.; FERNANDES, J. P.; OLIVEIRA, M. L. A.; PAZ, V. P. S. Estratégias de uso de água salobra na produção de alface em hidroponia NFT. Revista Brasileira de Engenharia Agrícola e Ambiental, v.15, n.5, p.491-498, 2011.

CAZUZA NETO, A.; SOARES, T. M.; BIONE, M. A.; FREITAS, F. T. O.; MELO, D. M.; SILVA FILHO, J. A. Qualidade do molho de coentro produzido em água salobra em sistema hidropônico NFT. In: II Brazilian Symposium on Salinity \& II Brazilian Meeting on Irrigation Engineering, Fortaleza. Anais... II INOVAGRI International Meeting: Fortaleza, 2014a. p.36783684.

CAZUZA NETO, A.; SOARES, T. M.; BIONE, M. A.; FREITAS, F. T. O.; MELO, D. M.; SILVA FILHO, J. A. Efeito da salinidade no consumo hídrico do molho de coentro produzido em sistema hidropônico NFT. In: II Brazilian Symposium on Salinity \& II Brazilian Meeting on Irrigation Engineering, Fortaleza. Anais... II INOVAGRI International Meeting: Fortaleza, 2014b. p.3685-3693.

DONEGÁ, M. A. Relação K:Ca e aplicação de silício na solução nutritiva para o cultivo hidropônica de coentro. 2009. 62p. Dissertação (Mestrado em Fitotecnia) - Escola Superior de Agricultura "Luiz de Queiroz", Universidade de São Paulo, Piracicaba, 2009.

FERREIRA NETO, M.; MIRANDA, R. S.; PRISCO, J. T.; GOMES-FILHO, E. Changes in growth parameters and biochemical mechanisms of coriander plants irrigated with saline water. In: II Brazilian Symposium on Salinity \& II Brazilian Meeting on Irrigation Engineering, Fortaleza. Anais... II INOVAGRI International Meeting: Fortaleza, 2014. p.3843-3850.

FURLANI, P. R.; SILVEIRA, L. C. P.; BOLONHEZI, D.; FAQUIN, V. Cultivo hidropônico de plantas. Campinas: IAC, 1999a. 52p. (Boletim Técnico, 180).
FURLANI, P. R.; SILVEIRA, L. C. P.; BOLONHEZI, D.; FAQUIN, V. Estruturas para o cultivo hidropônico. Informe Agropecuário, v.20, n.200/201, p.72-80, 1999 b.

LIRA, R. M.; SILVA, E. F. F.; SILVA, G. F.; SANTOS, A. N.; ROLIM, M. M. Production, water consumption and nutrient content of Chinese cabbage grown hydroponically in brackish water. Revista Ciência Agronômica, v.46, n.3, p.497-505, 2015.

PAULUS, D.; DOURADO NETO, D.; FRIZZONE, J. A.; SOARES, T. M. Produção e indicadores fisiológicos de alface sob hidroponia com água salina. Horticultura Brasileira, v.28, n.1, p.29-35, 2010.

PAULUS, D.; DOURADO NETO, D.; PAULUS, E. Análise sensorial, teores de nitrato e de nutrientes de alface cultivada em hidroponia sob águas salinas. Horticultura Brasileira, v.30, n.1, p.18-25, 2012a.

PAULUS, D.; PAULUS, E.; NAVA, G. A.; MOURA, C. A. Crescimento, consumo hídrico e composição mineral de alface cultivada em hidroponia com águas salinas. Revista Ceres, v.59, n.1, p.110-117, 2012 b.

SANTOS, A. N.; SILVA, E. F. F.; SOARES, T. M.; DANTAS, R. M. L.; SILVA, M. M. Produção de alface em NFT e Floating aproveitando água salobra $\mathrm{e} o$ rejeito da dessalinização. Revista Ciência Agronômica, v.42, n.2, p.319-326, 2011.

SANTOS, A. N.; SOARES, T. M.; SILVA, E. F. F.; SILVA, D. J. R.; MONTENEGRO, A. A. A. Cultivo hidropônico de alface com água salobra subterrânea e rejeito da dessalinização em Ibimirim, PE. Revista Brasileira de Engenharia Agrícola e Ambiental, v.14, n.9, p.961-969, 2010.

SILVA, A. O.; SILVA, D. J. R.; SOARES, T. M.; SILVA, E. F. F.; SANTOS, A. N.; ROLIM, M. M. Produção de rúcula em sistema hidropônico NFT utilizando água salina do Semiárido - PE e rejeito de dessalinizador. 
Revista Brasileira de Ciências Agrárias, v.6, n.1, p.147-155, 2011.

SILVA, M. G. Uso de água salobra e frequência de recirculação de solução nutritiva para produção de coentro hidropônico. 2014. 185p. Dissertação (Mestrado em Engenharia Agrícola) - Universidade Federal do Recôncavo da Bahia/Centro de Ciências Agrárias, Ambientais e Biológicas, Cruz das Almas, BA, 2014.

SOARES, H. R.; SILVA, E. F. F.; SILVA, G. F.; PEDROSA, E. M. R.; ROLIM, M. M.; SANTOS, A. N. Lettuce growth and water consumption in NFT hydroponic system using brackish water. Revista Brasileira de Engenharia Agrícola e Ambiental, v.19, n.7, p.636-642, 2015.

SOARES, T. M.; DUARTE, S. N.; SILVA, E. F. F.; JORGE, C. A. Combinação de águas doce e salobra para produção de alface hidropônica. Revista Brasileira de Engenharia Agrícola e Ambiental, v.14, n.7, p.705-714, 2010.

SOARES, T. M.; SILVA, E. F. F.; DUARTE, S. N.; MELO, R. F.; JORGE, C. A.; BONFIMSILVA, E. M. Produção de alface utilizando aguas salinas em sistema hidropônico. Irriga, v.12, n.2, p.235-248, 2007. 